\title{
The systemic administration of lethal toxin achieves a growth delay of human melanoma and neuroblastoma xenografts: Assessment of receptor contribution
}

\author{
CECILE ROULEAU $^{1}$, KRISHNA MENON ${ }^{7}$, PAULA BOUTIN $^{1}$, CHERYL GUYRE $^{1}$, HITOSHI YOSHIDA $^{3}$, \\ SHIRO KATAOKA ${ }^{4}$, MICHAEL PERRICONE ${ }^{1}$, SRINIVAS SHANKARA ${ }^{1}$, ARTHUR E. FRANKEL $^{5}$, \\ NICHOLAS S. DUESBERY ${ }^{6}$, GEORGE VANDE WOUDE ${ }^{6}$, HANS-PETER BIEMANN ${ }^{2}$ and BEVERLY A. TEICHER ${ }^{1}$ \\ ${ }^{1}$ Genzyme Corporation, Framingham, MA; ${ }^{2}$ Genzyme Corporation, Waltham, MA; ${ }^{3}$ Gemini Science Inc., San Diego, \\ CA, USA; ${ }^{4}$ Kirin Pharma Company Ltd., Takasaki, Japan; ${ }^{5}$ Cancer Research Institute, Scott and White Memorial \\ Hospital, Temple, TX; ${ }^{6}$ Van Andel Research Institute, Grand Rapids, MI; ${ }^{7}$ KARD Scientific, Cambridge, MA, USA
}

Received November 9, 2007; Accepted December 27, 2007

\begin{abstract}
Two of the three components of anthrax toxin, protective antigen (PA) and lethal factor (LF), together known as lethal toxin (LeTx), reportedly show anti-tumor activity in melanoma in vitro and in vivo. The growth inhibitory activity of LeTx in culture was determined in nine human cancer cell lines, including melanoma, neuroblastoma and adenocarcinoma cells, as well as in human umbilical vein endothelial cells (HUVEC). The contribution of the two known PA receptor proteins, ANTXR1/TEM8 and ANTXR2/ CMG2, to the sensitivity of the cells was assessed. The efficacy of LeTx was evaluated in vivo in the SK-N-AS neuroblastoma and SK-MEL-28 melanoma tumor xenograft models. Sensitivity to LeTx in vitro was observed in the neuroblastoma and colorectal adenocarcinoma cells and HUVEC, as well as melanoma cells. ANTXR1/TEM8 and ANTXR2/CMG2 protein expression studies suggested that a certain threshold of the PA receptor protein level must be met for sensitivity to LeTx to be observed. However, although the SK-N-AS neuroblastoma cells expressed the highest levels of receptor proteins and achieved the lowest $\mathrm{IC}_{50}$ in vitro $(0.1 \mathrm{ng} / \mathrm{ml})$, we observed no correlation between either the ANTXR1/ TEM8 or ANTXR2/CMG2 protein levels and sensitivity to LeTx in vitro. In vivo, LeTx was an active anti-tumor agent when administered intravenously to mice bearing the human SK-N-AS or SK-MEL-28 tumor xenografts. The tumor growth delays were 6-8 days with a lower dose regimen and
\end{abstract}

Correspondence to: Cecile Rouleau, Genzyme Corporation, 49 New York Avenue, Framingham, MA 01701, USA

E-mail: cecile.rouleau@genzyme.com

Key words: anthrax toxin, lethal toxin, protective antigen, lethal factor, cell growth inhibition, human xenograft, receptor protein expression, ANTXR1/TEM8, ANTXR2/CMG2, angiogenesis
14-16 days with a higher dose regimen for the two tumor models. These in vitro data suggest that LeTx may have broad therapeutic indications in cancer and the in vivo studies demonstrate that LeTx has systemic efficacy in neuroblastoma as well as melanoma. The therapeutic potential of LeTx needs to be further investigated in non-melanoma tumor models expressing the ANTXR1/TEM8 and/or ANTXR2/CMG2 protein.

\section{Introduction}

The infectious agent, Bacillus anthracis, has been known since ancient times (1). In 1881, Louis Pasteur developed the first anthrax vaccine. Although many details regarding the bacterial infection, proliferation and toxin production by Bacillus anthracis are understood, exactly how anthrax kills the host remains an area of investigation. In the mid-1980s, investigators at the US Army Medical Research Institute found differences in the susceptibility of inbred mice to Bacillus anthracis lethality (2). Moayeri et al (3) found that $\mathrm{Balb} / \mathrm{c}$ mice were much more sensitive to lethality after exposure to two components of the anthrax toxin (protective antigen plus lethal factor, called lethal toxin) than were C57BL/6J mice. After exposure, Balb/c mice had a rapid, transitory increase in several cytokines, excluding TNF- $\alpha$, while C57BL/6J mice did not. The cause of lethality appeared to be hypoxic tissue injury that did not require macrophage sensitivity to the toxin. The anthrax toxin acts on both macrophages and dendritic cells causing the inhibition of pro-inflammatory cytokine secretion, down-regulation of costimulatory molecules and ineffective T-cell priming $(4,5)$. Thus, the innate and adaptive immune response is impaired. Hemorrhage and pleural effusion are prominent pathological features of systemic anthrax infection. Warfel et al (6) examined the effect of anthrax lethal toxin on the barrier function of primary human lung microvascular endothelial cells in culture. Exposure to lethal toxin caused barrier dysfunction that did not depend on endothelial cell apoptosis or necrosis and supports a role for lethal toxin-induced barrier 
dysfunction in the vascular permeability changes that occur with infection. This suppression of immune cells and cytokine responses promotes bacterial outgrowth (7).

The anthrax toxin is composed of three proteins secreted by Bacillus anthracis (8-10) which are the pore-forming protein called protective antigen and two enzymes called edema (EF) and lethal factor (LF). The initial binding between $\mathrm{PA}$ and the cell surface receptor tumor endothelial marker 8 (ANTXR1/TEM8) or capillary morphogenesis gene 2 (ANTXR2/CMG2) is critical to the process (11-16). The proteolytic activation by furin allows for the oligomerization of PA into a heptamer and subsequent binding of up to three molecules of LF (17). The toxin receptor complex is then internalized into endosomes where the low $\mathrm{pH}$ causes a conformational change in PA so that it forms a pore through which LF escapes to the cytosol (18). LF is a metalloproteinase that cleaves mitogen-activated kinase kinases and EF is a calcium-calmodulin-dependent adenylate cyclase $(19,20)$.

The potential anti-tumor activity of the combination of two out of the three components of Bacillus anthracis exotoxin, PA and LF, together known as lethal toxin (LeTx), was first observed by testing in the 60 -cell line panel screen of the National Cancer Institute (21). Since melanoma cell lines had a higher than average sensitivity to LeTx, subsequent research on the potential therapeutic benefit of LeTx focused on melanoma. In 1998, Duesbery et al (22) identified the substrates of the proteolytic activity of LF as mitogenactivated protein kinase kinases 1 and 2 (MAPKK 1/2). The first evidence of LeTx systemic anti-tumor activity was in ras-transformed NIH 3 T3 cells as a model of a tumor. Tumor nodules were grown in the two flanks of nude mice and LeTx was administered by a local intratumoral injection into one nodule. A growth delay was observed in the two nodules indicating the systemic anti-tumor activity of LeTx. Tumors in animals treated with LeTx had a decreased neovascularization as compared with the controls (23). In 2002, Koo et al (24) demonstrated an induction of $\mathrm{G}_{1}$ arrest and apoptosis through MEK/MAPK signaling inhibition by LeTx in human melanoma cell lines. Systemic anti-tumor activity was observed in a human melanoma xenograft because the intratumoral and subcutaneous LeTx injection of right-side tumors resulted in a growth delay of tumors in the two flanks. Recently, Abi-Habib et al (25) demonstrated systemic antitumor activity by intraperitoneal injection of LeTx in mice in the SK-MEL-28 human melanoma xenograft model.

Uptake into the cells is critical in anthrax infection and pathogenesis. The therapeutic application of LeTx is guided by the expression of ANTXR1/TEM8 or ANTXR2/CMG2 on the cell surface (16). Abi-Habib et al (26) studied the PA receptor protein level and sensitivity to LeTx in a panel of human melanoma cell lines and normal human cells. The study showed that receptor levels did not correlate with sensitivity to LeTx, but that the presence of the BRAF V599E mutation and elevated levels of MEK 1/2 correlated with the responsiveness to LeTx exposure. However, the study did not distinguish between the two receptors and relied on cellbinding assays with radiolabeled PA to detect and quantify all PA binding sites.

As we undertook to evaluate the anti-tumor activity of LeTx in melanoma and non-melanoma human cancer models, we sought to correlate individually the level of each of the two LeTx receptor proteins, ANTXR1/TEM8 and ANTXR2/ CMG2, with cellular sensitivity to LeTx in vitro and human tumor xenograft responsiveness to systemic LeTx administration.

\section{Materials and methods}

Materials. The cell lines were purchased from the American Type Culture Collection (Manassas, VA). SK-N-AS was derived from a poorly-differentiated embryonal neuroblastoma bone marrow metastasis from a 6-year-old female child in 1981 (27). SK-MEL-28 was derived from a malignant melanoma skin lesion from a 51-year-old male in the early 1970s $(28,29)$. A-375 was derived from a malignant melanoma skin lesion from a 54-year-old female in 1973 (30). HT-29 was developed from the primary colon tumor of a 44-year-old female in 1964 (31). WM-115 was developed from a malignant melanoma skin lesion from a 58-year-old female in the early 1980s (32). SW-480 was derived from Dukes' stage B colorectal adenocarcinoma primary tumor of a 50-yearold male in the early 1970s (33). SK-BR-3 was developed from a breast adenocarcinoma pleural effusion metastasis from a 43-year-old female in 1970 (34). MCF-7 was developed from a breast adenocarcinoma pleural effusion metastasis from a 69-year-old female in the early 1970s (35). MEL-624 is a melanoma originally developed at NCI $(36,37)$. All of the human tumor cell lines were grown in RPMI (Invitrogen, Carlsbad, CA) supplemented with $10 \%$ fetal bovine serum (FBS) (Invitrogen). HEK293 cells stably transfected with ANTXR1/TEM8 were maintained in $500 \mu \mathrm{g} / \mathrm{ml} \mathrm{G} 418$ (Invitrogen). Primary human umbilical vein endothelial cells (HUVEC) were purchased from Cambrex (East Rutherford, $\mathrm{NJ}$ ) and grown in EGM2-MV (Cambrex). The recombinant proteins $\mathrm{LF}$ and PA were produced as previously described $(38,39)$. Mouse anti-human $\beta$-actin monoclonal antibody was purchased from Sigma-Aldrich (St. Louis, MO). Goat antihuman ANTXR2/CMG2 polyclonal antibody was purchased from R\&D Systems (Minneapolis, MN). The anti-human ANTXR1/TEM8 antibody is a fully human monoclonal antibody isolated after inoculation of the $\mathrm{KM}^{\mathrm{TM}}$ (Kirin Pharma Company Ltd.) mouse. The control antibody is a fully human antibody raised against dinitrophenol (DNP) in the $\mathrm{KM}^{\mathrm{TM}}$ mouse following the same inoculation and isolation protocols used for the ANTXR1/TEM8 antibody.

In vitro growth inhibition assays. The tumor cells were suspended by exposure to $0.25 \%$ trypsin in EDTA (Invitrogen, Inc., Carlsbad, CA) and washed once in RPMI/2\% FBS (Invitrogen, Inc.). Then, 2,000 cells were seeded per well in a 96-well format in RPMI/2\% FBS $(0.1 \mathrm{ml})$. Each experimental point was set up in duplicate wells. The cells were incubated for $24 \mathrm{~h}$ to allow recovery from trypsinization, after which they were exposed to PA $(100 \mathrm{ng} / \mathrm{ml})$ alone or PA $(100 \mathrm{ng} / \mathrm{ml})$ and $\mathrm{LF}(0.1,0.3,1,3$ or $10 \mathrm{ng} / \mathrm{ml})$ in RPMI $/ 2 \% \mathrm{FBS}(0.1 \mathrm{ml})$ for $72 \mathrm{~h}$. HUVEC were suspended by exposure to $0.25 \%$ trypsin in EDTA and washed once in EBM2/2\% FBS (Cambrex). Thereafter, 2,000 HUVEC were seeded per well in a 96-well format in EBM2/2\% FBS $(0.1 \mathrm{ml})$. Each experimental point was set up in duplicate wells. HUVEC 
were incubated for $24 \mathrm{~h}$ to allow recovery from trypsinization, after which they were exposed to PA $(100 \mathrm{ng} / \mathrm{ml})$ alone or PA $(100 \mathrm{ng} / \mathrm{ml})$ and $\operatorname{LF}(0.1,0.3,1,3$ or $10 \mathrm{ng} / \mathrm{ml})$ in EBM $2 / 2 \%$ FBS $(0.1 \mathrm{ml})$ for $72 \mathrm{~h}$. Following the $72 \mathrm{~h}$ exposure to PA or LeTx, WST-1 reagent (10 $\mu 1$, BioVision Research Products, Mountain View, CA) was added to each well and cultures were maintained for $30 \mathrm{~min}$ at $37^{\circ} \mathrm{C}(40)$. Measurement of the absorbance at $440 \mathrm{~nm}$ allowed for the quantification of the formazan dye. A reference wavelength of $650 \mathrm{~nm}$ was used as per manufacturer recommendation. The $650 \mathrm{~nm}$ reference absorbance was subtracted from the $440 \mathrm{~nm}$ one. The background was measured using a well-containing medium only. All incubations took place at $37^{\circ} \mathrm{C}$ in a humified $5 \%$ carbon dioxide atmosphere. The results are the means of two independent determinations, error is SEM. Data were analyzed using a non-linear regression (sigmoidal doseresponse curve, variable slope) with the GraphPad Prism software (GraphPad Software, Inc., San Diego, CA).

The cloning of ANTXR1/TEM8. The full-length ANTXR1/ TEM8 sequence was amplified by PCR from a fetal brain cDNA library (Invitrogen). The primers used for amplification were CCACCATGGCCACGGCGGAGCGGAGAGCC (forward primer) and TCACCACTCCTCTTCTCTAACTGG (reverse primer). Briefly, 5 pmol of primer was mixed with $1 \mu \mathrm{g}$ of fetal brain cDNA in a reaction containing $1 \mathrm{mM} \mathrm{Mg}$ at $\mathrm{pH}$ 9.0. PCR cycling conditions were $94^{\circ} \mathrm{C}$ for $2 \mathrm{~min}$ to denature the cDNA, then $94^{\circ} \mathrm{C}$ for $1 \mathrm{~min}, 55^{\circ} \mathrm{C}$ for $2 \mathrm{~min}$, $72^{\circ} \mathrm{C}$ for $3 \mathrm{~min}$ for 31 cycles with a final extension at $72^{\circ} \mathrm{C}$ for $7 \mathrm{~min}$. The resulting sequence contained the 1780 nucleotide open reading frame of the ANTXR1/TEM8 receptor. This sequence is identical to Genbank NM_032208.1 homo sapiens anthrax toxin receptor variant 1 (ANTXR1). The fragment was isolated on an agarose gel and cloned in pcDNA3.1/V5-His-TOPO (Invitrogen).

The stable transfection of the HEK293 cells with ANTXR1/ TEM8. The HEK293 cells were transfected with the fulllength ANTXR1/TEM8 cDNA using lipofectamine (Invitrogen). Stable transfection was achieved by exposure to $500 \mu \mathrm{g} / \mathrm{ml} \mathrm{G} 418$ (Invitrogen).

ANTXR1/TEM8 protein expression, flow cytometry. Cells were suspended by exposure to Versene (Invitrogen), then the cells $\left(10^{5}\right)$ were incubated with anti-ANTXR1/TEM8 or anti-DNP primary antibody $(40 \mu \mathrm{g} / \mathrm{ml}$, Kirin Pharma Co. Ltd., Takasaki, Japan) in PBS (Invitrogen) containing 5\% FBS (Invitrogen) $(25 \mu \mathrm{l})$ for $1 \mathrm{~h}$ on ice. Cells were washed 3 times in cold $\mathrm{PBS} / 5 \%$ FBS. After washing, the cells were incubated with phycoerythrin (PE)-labeled anti-human $\mathrm{IgG}$ diluted 1:40 (Jackson ImmunoResearch Laboratories, Inc., West Grove, PA) for $1 \mathrm{~h}$ on ice. After washing 3 times in cold PBS/5\% FBS, the cells were suspended in cold PBS/5\% FBS (300 $\mu \mathrm{l})$ and kept on ice. Flow cytometry was conducted on a FACSCalibur (Becton-Dickinson Labware, Franklin Lakes, NJ). Events were gated according to forward (FSC) and side scatter (SSC), events with the lowest and highest FSC/SSC were excluded from the gate. An ANTXR1/TEM8 signal was acquired using the FL2 channel through the use of the PEconjugated secondary antibody. Alternatively, 7-amino- actinomycin D (7-AAD) (Invitrogen) (20 $\mu \mathrm{l})$ was added $10 \mathrm{~min}$ before acquisition. Events were gated according to 7-AAD status. The ANTXR1/TEM8 signal was acquired using the FL1 channel through a FITC-conjugated secondary antibody (Jackson ImmunoResearch Laboratories, Inc.). The 7-AAD signal was acquired using the FL3 channel. 7-AAD-positive cells were excluded from the gate. An ANTXR1/TEM8 signal profile was compared to the DNP signal profile. Data were reproduced in at least two independent experiments.

ANTXR2/CMG2 protein expression, Western blotting. Tissue culture dishes $\left(100 \mathrm{~cm}^{2}\right)$ containing near-confluent cultures were placed on ice. The medium was aspirated and the cells washed once with cold PBS. Cold PBS (1 ml) was added to the cultures and the cells were removed by scraping using a cell scraper. The cells were suspended in PBS $(1 \mathrm{ml})$ and transferred to a centrifuge tube $(1.5 \mathrm{ml})$ and centrifuged for $5 \mathrm{~min}$ at $4^{\circ} \mathrm{C}$ at 2,000 rpm. Afterwards, the supernatant was removed and discarded. Cell lysis buffer was added [150 mM $\mathrm{NaCl}, 50 \mathrm{mM}$ Tris $\mathrm{pH} \mathrm{7.5,0.5 \%} \mathrm{NP40} \mathrm{and} \mathrm{proteinase}$ inhibitor cocktail tablets (Roche Diagnostics, Basel, Switzerland) in sterile $\mathrm{ddH}_{2} \mathrm{O}$ ] and triturated to obtain an even suspension. A volume of lysis buffer added to each sample was 5 times the volume of the cell pellet. Lysates were incubated on ice for $30 \mathrm{~min}$, then centrifuged for $15 \mathrm{~min}$ at $4^{\circ} \mathrm{C}$ at $14,000 \mathrm{rpm}$. The total protein content of each supernatant was determined using the BCA protein assay kit (Pierce Biotechnology, Rockford, IL), according to the manufacturer's instructions.

Each protein sample $(40 \mu \mathrm{g})$ was mixed with a NuPage reducing agent and LDS sample buffer (Invitrogen) as per the manufacturer's instructions, heated to $70^{\circ} \mathrm{C}$ for $10 \mathrm{~min}$ and loaded into one lane of a $4-12 \%$ Novex Bis-Tris gel (Invitrogen). Electrophoresis was conducted for $30 \mathrm{~min}$ at $200 \mathrm{~V}$ using a NuPage MES running buffer and NuPage antioxidant (Invitrogen) according to the manufacturer's instructions. The gel was transferred to a Hybond ECL nitrocellulose membrane (GE Healthcare, Piscataway, NJ) in NuPage transfer buffer (Invitrogen) at $25 \mathrm{~V}$ for $35 \mathrm{~min}$ as per the manufacturer's instructions. The membrane was blocked for $1 \mathrm{~h}$ at room temperature in 5\% milk (BioRad, Hercules, $\mathrm{CA}$ ) and PBS (Invitrogen) supplemented with $0.1 \%$ Tween20 (Sigma-Aldrich) (PBST), incubated in either antiANTXR2/CMG2 primary antibody (R\&D Systems) diluted at $1: 1.000$ or anti- $\beta$-actin (Sigma-Aldrich) diluted at 1:10.000 and washed 3 times for $15 \mathrm{~min}$ in PBST at room temperature. The membrane was then incubated with the speciesappropriate HRP-conjugated secondary antibody (Jackson ImmunoResearch Laboratories, Inc.) diluted at 1:1000 in 5\% milk in PBST for $1 \mathrm{~h}$ at room temperature. The membrane was rinsed 3 times in PBST, washed 3 times for $15 \mathrm{~min}$ in PBST at room temperature and developed using the ECL Plus Western Blotting Detection System (GE Healthcare). For the densitometric analysis, the film was scanned using the Gel Logic 2200 instrument (Kodak, Rochester, NY) and bands were quantified using the ImageMaster 1D v4.10 software (GE Healthcare).

Human tumor xenograft experiments. The SK-N-AS or SKMEL-28 cells $\left(2 \times 10^{6}\right)$ prepared from donor tumors were 


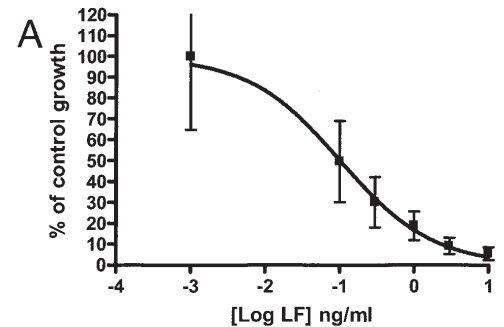

- SK-N-AS

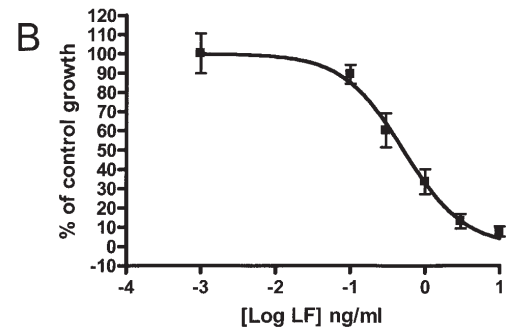

- HT-29

C

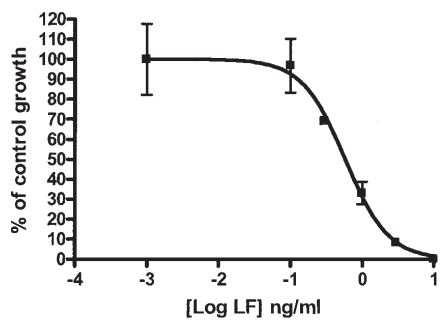

- SK-MEL-28
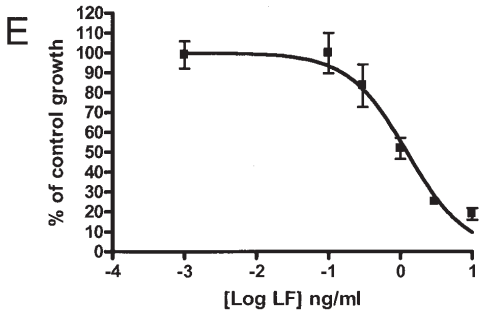

G

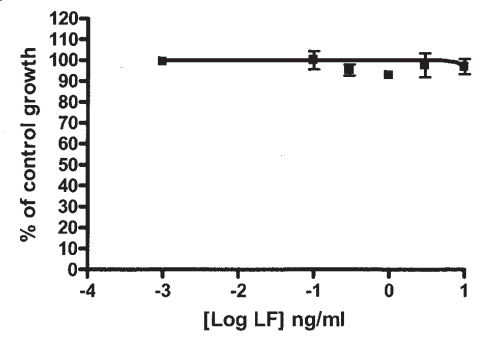

I

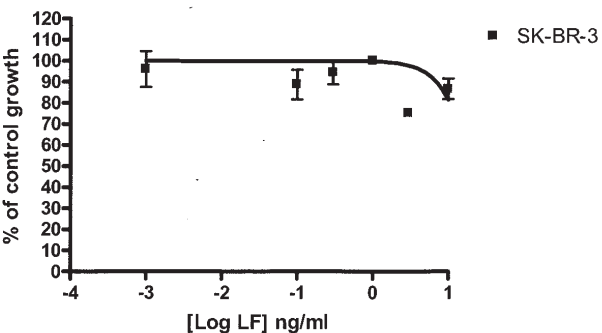

WM-115
F
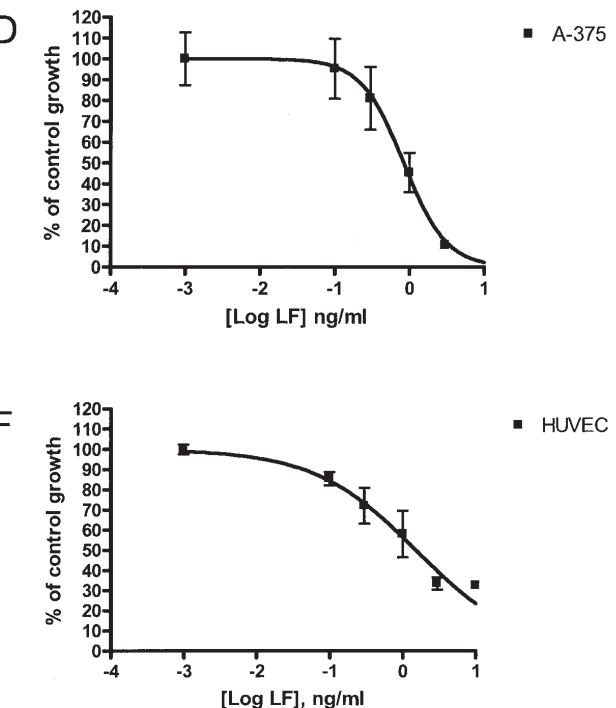

$\mathrm{H}$

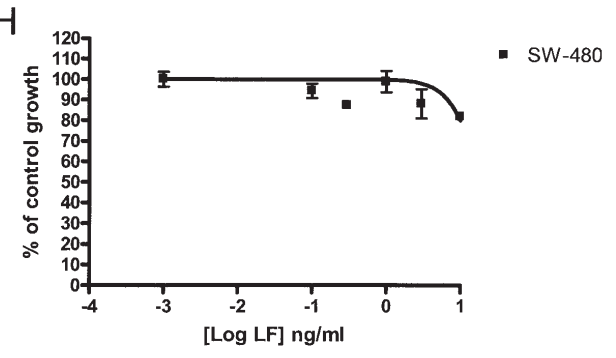

$J$

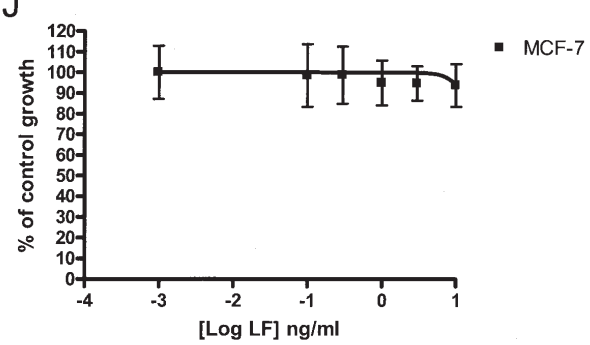

Figure 1. LeTx inhibits the growth of human cells in culture. The growth of human SK-N-AS neuroblastoma cells (A), HT-29 colorectal adenocarcinoma cells (B), SK-MEL-28 melanoma cells (C), A-375 melanoma cells (D), WM-115 melanoma cells (E), HUVEC (F), MEL-624 melanoma cells (G), SW-480 colorectal adenocarcinoma cells (H), SK-BR-3 breast adenocarcinoma cells (I) and MCF-7 breast adenocarcinoma cells (J) with the anthrax protective antigen (PA) $(100 \mathrm{ng} / \mathrm{ml})$ in combination with anthrax lethal factor (LF) $(0.1-10 \mathrm{ng} / \mathrm{ml})$ to compose anthrax lethal toxin (LeTx) in $96-$ well cultures (2,000 cells per well). After $72 \mathrm{~h}$ of exposure, cellular growth was measured. The data are the means derived from two independent experiments.

implanted subcutaneously in 8-week-old female and male Balb/c nude mice, respectively (Charles River Laboratories, Andover, MA). The doses of LF chosen were reported to be non-toxic in either Balb/c or C57BL/6J mice (3). In the first experiment, tumor-bearing animals were treated with either PBS (vehicle), PA alone $(20 \mu \mathrm{g})$ or PA $(20 \mu \mathrm{g})+\mathrm{LF}(1 \mu \mathrm{g})$ with intravenous tail vein injection on alternate days beginning on day 9 post tumor cell implant and continuing until day 21 (total 7 doses). In the combined treatment group, PA was injected first and LF $1 \mathrm{~h}$ later. A sequential rather than simultaneous dosing of PA and LF was chosen in order to avoid the possible binding of the two proteins to each other in the solution. In the second experiment, tumor-bearing animals were either untreated, vehicle-treated or treated with either PA alone $(20 \mu \mathrm{g})$ or LF alone $(10 \mu \mathrm{g})$ or PA $(20 \mu \mathrm{g})+$ $\mathrm{LF}(10 \mu \mathrm{g})$ by an intravenous (iv) tail vein injection on 
Table I. Summary of the PA receptor expression and sensitivity to LeTx.

\begin{tabular}{lccc}
\hline Human cells & $\mathrm{IC}_{50} \mathrm{ng} / \mathrm{ml}$ & ANTXR1/TEM8 & ANTXR2/CMG2 \\
\hline SK-N-AS neuroblastoma & 0.1 & +++ & +++ \\
HT-29 colorectal adenocarcinoma & 0.5 & - & + \\
SK-MEL-28 melanoma & 0.6 & + & + \\
A-375 melanoma & 0.8 & - & + \\
WM-115 melanoma & 1.2 & - & ++ \\
HUVEC & 1.5 & $-/+$ & ++ \\
MEL-624 melanoma & $>10$ & - & - \\
SW-480 colorectal adenocarcinoma & $>10$ & - & - \\
SK-BR-3 breast adenocarcinoma & $>10$ & + & - \\
MCF-7 breast adenocarcinoma & $>10$ & & - \\
\hline
\end{tabular}

alternate days from day 7-19 (total 7 doses). In this experiment, for the combination treatment group, LF was administered $1 \mathrm{~h}$ prior to PA.

The progress of each tumor was measured twice weekly until it reached a volume of $4000 \mathrm{~mm}^{3}$. The tumor volume was calculated using the formula $\left(\mathrm{L} \mathrm{x} \mathrm{W}^{2}\right)$ 0.52. The tumor growth delay was calculated as the days taken by each individual tumor to reach $2000 \mathrm{~mm}^{3}$ compared with the untreated or vehicle-treated controls. Each treatment group consisted of 10 animals. The days of the tumor growth delay are the mean \pm SEM for the treatment group compared with the control (41).

\section{Results}

Cell growth inhibition assays. Two human breast adenocarcinoma cell lines, MCF-7 and SK-BR-3; two human colorectal adenocarcinoma cell lines, SW-480 and HT-29; four human melanoma cell lines, A-375, MEL-624, SK-MEL28 and WM-115; the human neuroblastoma cell line SK-NAS and human umbilical vein endothelial cells (HUVEC) were exposed to a concentration range of LeTx using a fixed PA concentration of $100 \mathrm{ng} / \mathrm{ml}$ and $\mathrm{LF}$ concentrations ranging from 0.1 to $10 \mathrm{ng} / \mathrm{ml}$ in a monolayer culture for $72 \mathrm{~h}$. Control wells were set up where cells were exposed to $100 \mathrm{ng} / \mathrm{ml} \mathrm{PA}$ alone in the absence of LF. The cell growth in these wells was comparable for all cell types to the growth observed with the medium alone, demonstrating that PA alone failed to induce growth inhibition (data not shown).

SK-N-AS neuroblastoma cells were most sensitive to LeTx with an $\mathrm{LF} \mathrm{IC}_{50}$ of $0.1 \mathrm{ng} / \mathrm{ml}$, followed by HT-29 colorectal adenocarcinoma cells $\left(\mathrm{IC}_{50}=0.5 \mathrm{ng} / \mathrm{ml}\right)$, SK-MEL-28 melanoma cells $\left(\mathrm{IC}_{50}=0.6 \mathrm{ng} / \mathrm{ml}\right)$, A-375 melanoma cells $\left(\mathrm{IC}_{50}=0.8 \mathrm{ng} / \mathrm{ml}\right), \mathrm{WM}-115$ melanoma cells $\left(\mathrm{IC}_{50}=1.2 \mathrm{ng} / \mathrm{ml}\right)$ and HUVEC $\left(\mathrm{IC}_{50}=1.5 \mathrm{ng} / \mathrm{ml}\right)$. Maximal growth inhibition was obtained with $3 \mathrm{ng} / \mathrm{ml}$ of LF, at which $70-100 \%$ growth inhibition was observed. In contrast, the MEL-624 melanoma cell line, MCF-7 and SK-BR-3 breast adenocarcinoma cell lines and the SW-480 colorectal adenocarcinoma cell line, with $\mathrm{LF} \mathrm{IC}_{50}$ values $>10 \mathrm{ng} / \mathrm{ml}$, appeared to resist LeTx (Fig. 1A-J and Table I).
The PA receptor protein expression. The expression of the two known PA receptors was examined on the 10 cell types. The availability of a monoclonal antibody to the human ANTXR1/TEM8 allowed for the use of fluorescence-activated cell sorting to detect this PA receptor on the cell surface. The human HEK-293 cells, engineered to express an empty vector or ANTXR1/TEM8, were used as a positive control (Fig. 2). High levels of the ANTXR1/TEM8 protein were detected by flow cytometry on SK-N-AS neuroblastoma cells. Low levels of the ANTXR1/TEM8 protein were detected in SK-MEL-28 and A-375 melanoma cells and MCF-7 breast adenocarcinoma cells. Marginal levels of ANTXR1/TEM8 were also detected in MEL-624 melanoma cells. ANTXR1/TEM8 was not detected in HT-29 and SW-480 colorectal adenocarcinoma, WM-115 melanoma and, SK-BR-3 breast adenocarcinoma cells or HUVEC (Fig. 2 and Table I).

ANTXR2/CMG2 protein levels were determined by Western blot analysis of whole cell lysates (Fig. 3). Western blotting yielded a single most prominent band with an approximate molecular weight of $54 \mathrm{kDa}$, consistent with the plasma membrane receptor isoform previously described as $\mathrm{CMG}^{489}$ (16). High levels of the ANTXR2/CMG2 protein were detected in SK-N-AS cells, WM-115 melanoma cells and HUVEC. The expression in HUVEC was consistent with the fact that ANTXR2/CMG2 was first identified in that cell type (15). Low levels of the ANTXR2/CMG2 protein were observed in SK-MEL-28 and A-375 melanoma cells and in HT-29 colorectal adenocarcinoma cells. Marginal ANTXR2/ CMG2 levels were detected in the MEL-624 melanoma cell line. The ANTXR2/CMG2 protein could not be detected in MCF-7 and SK-BR-3 breast adenocarcinoma cells or in SW-480 colorectal adenocarcinoma cells (Fig. 3 and Table I).

All 6 cell types sensitive to LeTx expressed the ANTXR2/CMG2 protein. Three of these, SK-N-AS, A-375 and SK-MEL-28, expressed ANTXR1/TEM8 as well as ANTXR2/CMG2 (double positive) while the other 3 , HUVEC, WM-115 and HT-29, were negative for ANTXR1/ TEM8. Among the 3 double positive responders, the SK-NAS neuroblastoma cell line expressed high levels of each receptor, while the other 2 double positive responders, A-375 and SK-MEL-28 melanoma, expressed low levels of each receptor. Among the 4 cell lines resistant to LeTx, two cell 

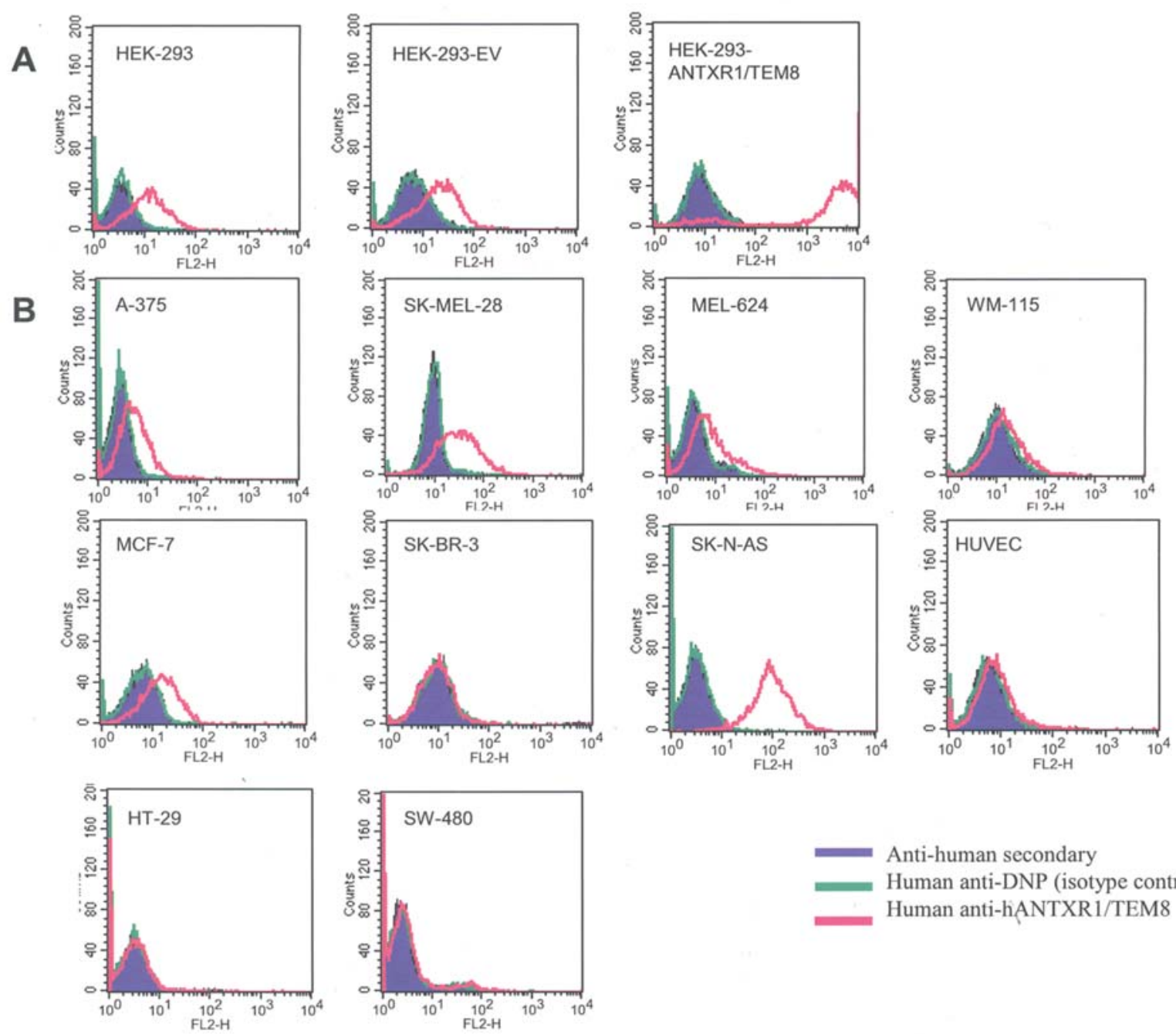

Figure 2. ANTXR1/TEM8 protein expression by flow cytometry. ANTXR1/TEM8 was detected using a fully human monoclonal antibody raised against the human ANTXR1/TEM8. The geometric mean fluorescence is shown on the y-axis. The ANTXR1/TEM8 protein level is shown on the $\mathrm{x}$-axis and is a function of the fluorescence of a phycoerythrin (PE)-labeled secondary antibody acquired using the FL2 channel. The ANTXR1/TEM8 flow cytometry profiles of the wild-type HEK-293 kidney epithelial and HEK-293 cells transfected with an empty vector or with a vector-encoding human ANTXR1/TEM8 (A). ANTXR1/TEM8 flow cytometry profiles for 10 human cell types (B). The data show a representative experiment.

A

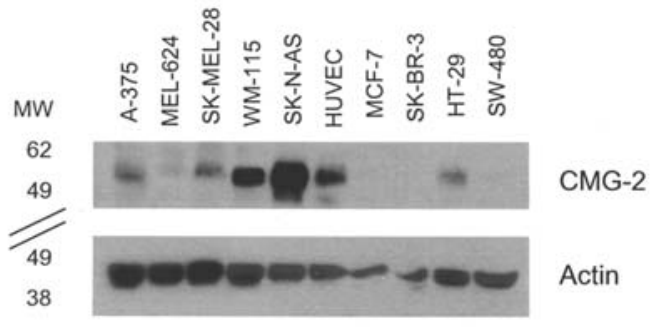

B

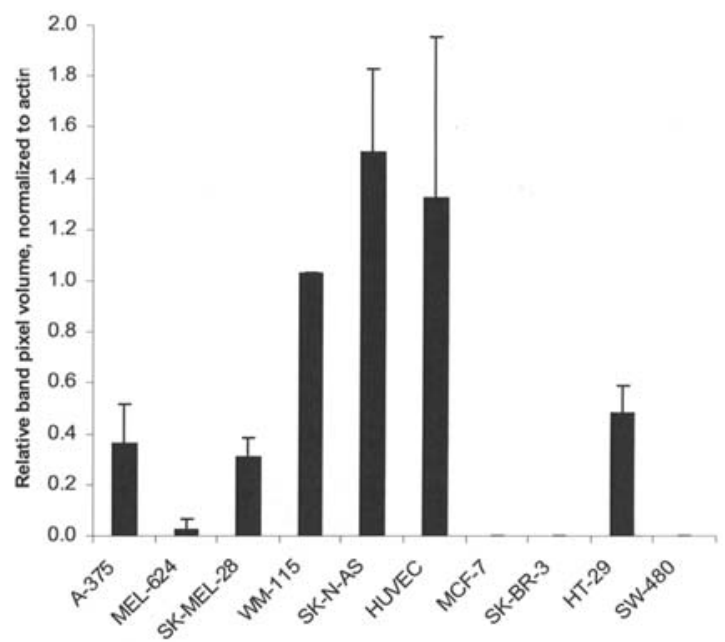

Figure 3. ANTXR2/CMG2 expression by Western blotting. A Western blot of whole cell lysates for 10 human cell types probed for the expression of ANTXR2/CMG2 and actin protein using anti-ANTXR2/CMG2 and anti-B-actin, respectively. A single representative Western blot is shown (A). Densitometry analysis of Western blot bands showing the relative expression of ANTXR2/CMG2 protein in the 10 human cell types. The ANTXR2/CMG2 protein levels are normalized to actin protein levels. The data represent the mean of two independent Western blots, error bars represent SD (B). 

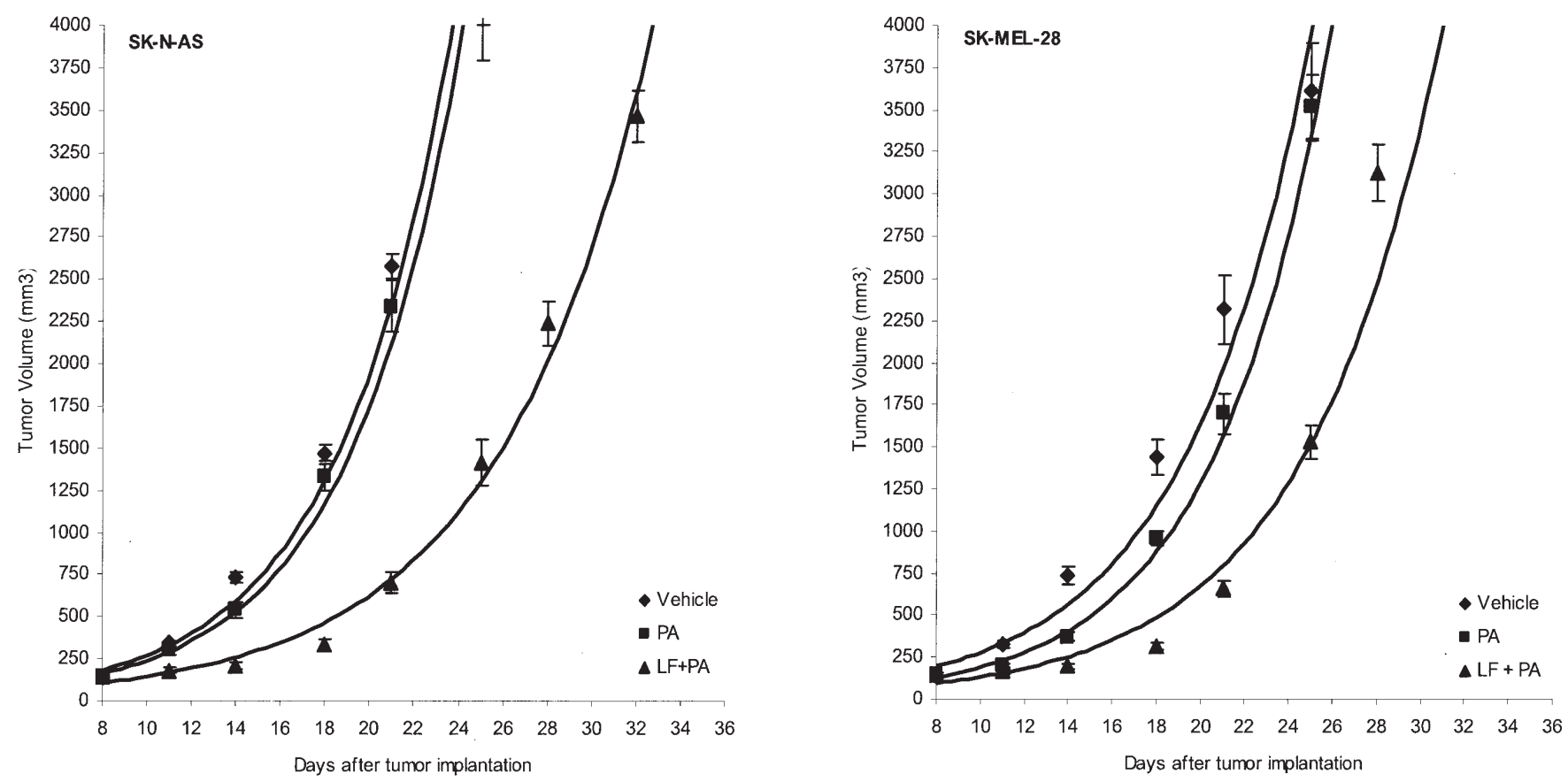

Figure 4. LeTx inhibits tumor growth in vivo, low dose. Growth of subcutaneously implanted human SK-N-AS neuroblastoma or SK-MEL-28 melanoma cell lines after treatment with vehicle intravenously (iv) or PA ( $20 \mu \mathrm{g} / \mathrm{dose}$, iv) or PA ( $20 \mu \mathrm{g} / \mathrm{dose}$, iv) followed $1 \mathrm{~h}$ later by LF (1 $\mu \mathrm{g} / \mathrm{dose}$, iv) on alternate days beginning on day 9 post tumor cell implantation and continuing until day 21 for a total of 7 doses. The data are the means of 10 animals, error bars represent SEM.

lines, SK-BR-3 and SW-480, expressed no receptor at all (double negative); one cell line, MCF-7, expressed low levels of ANTXR1/TEM8 but no ANTXR2/CMG2 and one cell line, MEL-624, expressed marginal levels of each receptor (Table I).

Human tumor xenograft models. Two human tumor cell lines sensitive to LeTx in culture and positive for the two PA receptors, SK-N-AS neuroblastoma and SK-MEL-28 melanoma, were implanted subcutaneously in nude mice using cells derived from donor tumors. When animals bearing the SK-N-AS neuroblastoma were treated with PA $(20 \mu \mathrm{g} /$ dose, iv) followed $1 \mathrm{~h}$ later by $\mathrm{LF}(1 \mu \mathrm{g} / \mathrm{dose}$, iv) on alternate days for days 9-21 post tumor cell implantation, a tumor growth delay of 7.7 days resulted compared to the vehicletreated controls. Treatment with PA $(20 \mu \mathrm{g} /$ dose, iv $)$ alone did not alter the growth of the tumor (Fig. 4). In a similar study, when animals bearing the SK-MEL-28 melanoma were treated with PA ( $20 \mu \mathrm{g} /$ dose, iv) followed $1 \mathrm{~h}$ later by LF (1 $\mu \mathrm{g} / \mathrm{dose}, \mathrm{iv})$ on alternate days for days 9-21 post tumor cell implantation, a tumor growth delay of 6.0 days resulted compared to the vehicle-treated controls. Treatment with PA $(20 \mu \mathrm{g} / \mathrm{dose}, \mathrm{iv})$ alone resulted in a tumor growth delay of 1.8 days (Fig. 4).

In the second series of experiments, the human SK-N-AS neuroblastoma xenograft was grown subcutaneously in female nude mice and the animals were treated with vehicle (iv), PA (20 $\mu \mathrm{g} /$ dose, iv), LF (10 $\mu \mathrm{g} /$ dose, iv) or LF $(10 \mu \mathrm{g} /$ dose, iv) followed $1 \mathrm{~h}$ later by PA $(20 \mu \mathrm{g} / \mathrm{dose}$, iv) on alternate days beginning on day 7 post tumor cell implantation and continuing until day 19 for a total of 7 doses (Fig. 5). The vehicle and LF treatment alone did not alter the growth of the tumor and treatment with PA alone resulted in a tumor growth delay of 3 days. The combination regimen with LF administered first in the sequence at a dose 10 times higher than in the first experiment produced a tumor growth delay of 14.3 days. In a similar study, male nude mice bearing the SK-MEL-28 melanoma were treated with vehicle iv, PA (20 $\mu \mathrm{g} / \mathrm{dose}, \mathrm{iv}), \mathrm{LF}(10 \mu \mathrm{g} / \mathrm{dose}, \mathrm{iv})$ or LF (10 $\mu \mathrm{g} / \mathrm{dose}, \mathrm{iv})$ followed $1 \mathrm{~h}$ later by PA $(20 \mu \mathrm{g} /$ dose, iv $)$ on alternate days beginning on day 7 post tumor cell implantation and continuing until day 19 for a total of 7 doses (Fig. 5). The vehicle and LF treatments had no effect on tumor growth and the PA treatment alone resulted in a tumor growth delay of 3.8 days. In this model, the combination regimen with LF administered first in the sequence at a dose 10 times higher than in the first experiment produced a tumor growth delay of 15.4 days. In the in vivo experiments the combination of PA and LF resulted in a body weight loss of $10 \%$.

\section{Discussion}

Anthrax lethal toxin (LeTx) is a targeted anticancer therapy. Two receptors for protective antigen (PA) have been described and it appears that at least a detectable level of one or both receptors is required for sensitivity to LeTx in cell culture. If these findings are sustained, it may be possible to identify patients who would benefit from LeTx therapy $(42,43)$.

We evaluated the growth inhibitory activity of LeTx in two human breast adenocarcinoma lines (MCF-7 and SKBR-3), two human colorectal adenocarcinoma lines (SW-480 and HT-29), four human melanoma lines (A-375, MEL-624, SK-MEL-28 and WM-115), one human neuroblastoma line (SK-N-AS) and HUVEC. Of the 10 cell types, 6 were growth-inhibited by LeTx. These were from most to least sensitive: SK-N-AS, HT-29, SK-MEL-28, A-375, WM-115 and HUVEC. Of the 10 cell types, 4 were not growth-inhibited 

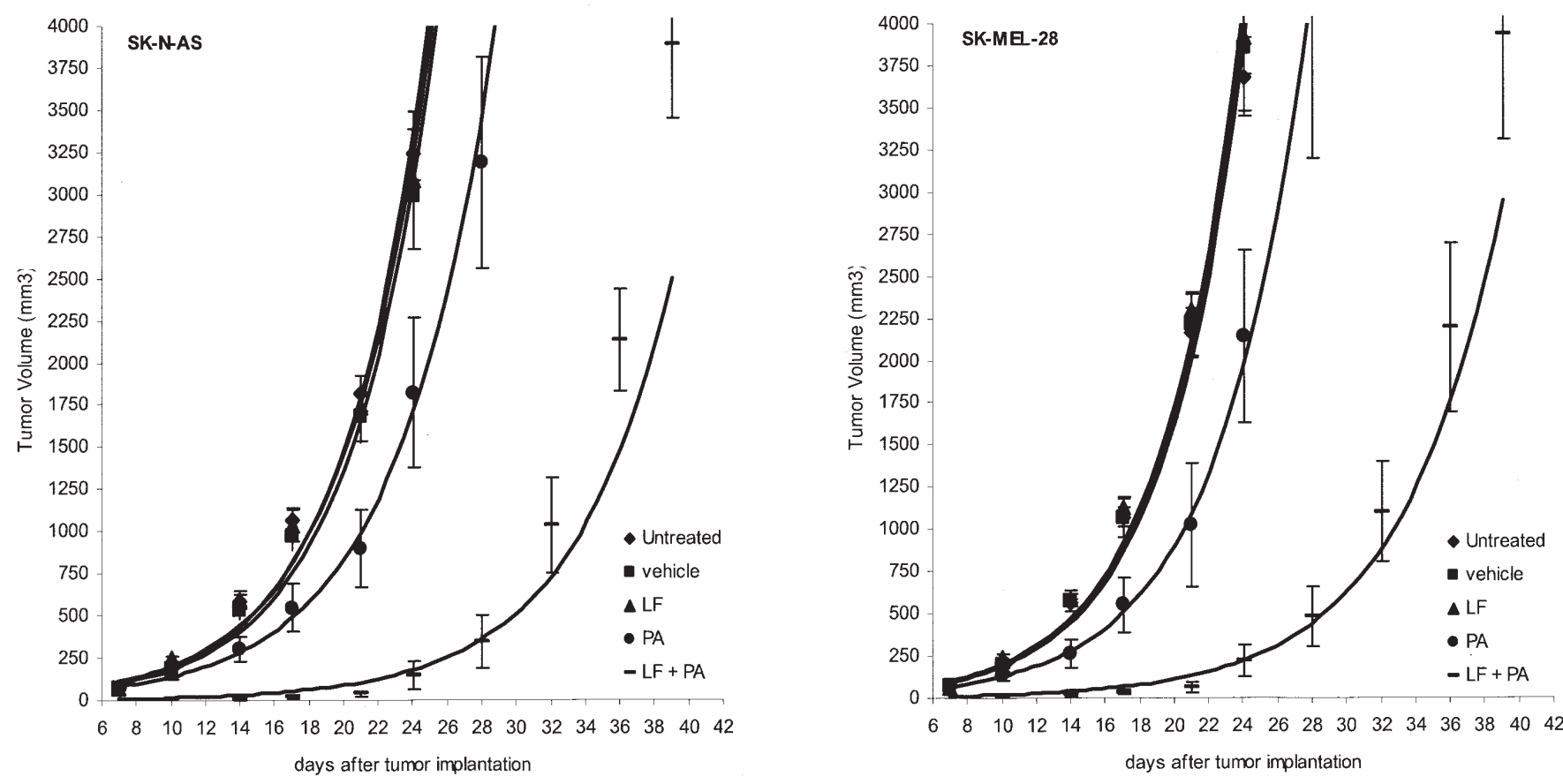

Figure 5. LeTx inhibits tumor growth in vivo, high dose. The growth of subcutaneously implanted human SK-N-AS neuroblastoma or SK-MEL-28 melanoma cell lines after treatment with vehicle intravenously (iv), PA ( $20 \mu \mathrm{g} / \mathrm{dose}$, iv), LF (10 $\mu \mathrm{g} / \mathrm{dose}$, iv) or LF (10 $\mu \mathrm{g} /$ dose, iv) followed $1 \mathrm{~h}$ later by PA ( $20 \mu \mathrm{g} / \mathrm{dose}$, iv) on alternate days beginning on day 7 post tumor cell implantation and continuing until day 19 for a total of 7 doses. The data are the means of 10 animals, error bars represent SEM.

by concentrations of LF up to $10 \mathrm{ng} / \mathrm{ml}$, these being MEL-624, SW-480, MCF-7 and SK-BR-3 (Fig. 1A-J and Table I).

In an attempt to associate the PA receptor expression with sensitivy to LeTx in vitro, flow cytometry was used to detect the expression of ANTXR1/TEM8 and Western blotting was used to determine the expression of ANTXR2/CMG2. The SK-N-AS neuroblastoma cell line expressed the highest level of the two receptors but was only 5-fold more sensitive to growth inhibition by LeTx in vitro than the HT-29 cell line that expressed low levels of only one of the two receptors (ANTXR2/CMG2). Similarly, WM-115 cells and HUVEC were $\sim 2$-fold less sensitive to LeTx than were the HT-29 cells, with approximately twice as much ANTXR2/CMG2 than HT-29 cells. In addition, the sensitivity of HT-29 cells to LeTx in vitro was comparable to that of SK-MEL-28 and A375 cells, which expressed low levels of ANTXR1/TEM8 and ANTXR2/CMG2. Notably, in the human tumor xenograft studies, SK-N-AS and SK-MEL-28 tumors were equivalently sensitive to LeTx therapy despite different levels of PA receptors in vitro, underscoring the notion that the over-expression of PA receptors may not provide markedly increased sensitivity in vitro or in vivo. It is noticeable that all 6 cell types sensitive to LeTx express ANTXR2/CMG2 while only 3 of them express ANTXR1/ TEM8. These data suggest that ANTXR2/CMG2 may play a more prominent role in anthrax pathogenesis than does ANTXR1/TEM8, based on an apparently broader expression, at least in this limited group of samples. Incidentally, ANTXR2/CMG2 was reported to have a higher affinity for PA than does ANTXR1/TEM8, providing additional evidence that ANTXR2/CMG2 may play a more critical role in anthrax infection than ANTXR1/TEM8 (18). In the scenario developed here, where doses of LeTx that do not trigger any course of disease are used for therapeutic purposes, it is possible that ANTXR2/CMG2 may be a more critical mediator of therapy than ANTXR1/TEM8.

Of the 4 non-responsive cell lines, 2 cell lines, SK-BR-3 breast adenocarcinoma and SW-480 colorectal adenocarcinoma, were negative for the two receptors; one cell line, MCF-7 breast adenocarcinoma, expressed low levels of ANTXR1/TEM8 but no detectable ANTXR2/CMG2 and one cell line, the MEL-624 melanoma cell line, expressed marginal levels of ANTXR1/TEM8 and ANTXR2/CMG2. These results suggest that a certain threshold of the PA receptor level must be met in order to allow entry of LF into cells, and that cells such as MEL-624 and MCF-7 were below that threshold and therefore resistant to LeTx.

Previous studies in melanoma showed that intracellular factors such as BRAF mutations and MEK1/2 levels are the most critical parameters in determining sensitivity $(22,26,44)$. The intracellular proteins targeted by LeTx have yet to be studied in non-melanoma tumor cells. Macrophages, which are at the center of the symptoms of anthrax infection, may provide clues as to which cellular parameters may play a role in the sensitivity or resistance of human cancer cells to LeTx, such as proteasome activity, intracellular calcium stores or protein synthesis (45-49). Alternatively, co-factors required for the binding of ANTXR1/TEM8 or ANTXR2/ $\mathrm{CMG} 2$ to PA or for the internalization of the toxin-receptor complex, such as members of the LDL receptor family, may turn out to correlate better with response $(50,51)$.

The LeTx anti-tumor effect by intravenous administration of PA and LF as separate consecutive injections was dosedependent with efficacy (6-8 days TGD), achieved at the low dose (1 $\mu \mathrm{g}$ LF) and greater efficacy (14-16 days TGD), achieved with the high dose regimen (10 $\mu \mathrm{g} \mathrm{LF})$. Greater 
efficacy was also observed when LF was administered before rather than after PA. This suggests that the tumor dose of LF is dependent upon PA availability and is consistent with earlier observations that PA is rapidly sequestered from circulation following iv injection (52). These data represent the first evidence of systemic anti-tumor activity by LeTx in a non-melanoma tumor model without reliance on an intratumoral injection and suggest that the potential therapeutic benefit of LeTx in cancer may extend beyond melanoma, although cellular factors regulating sensitivity to LeTx in non-melanoma cells are unknown at the moment.

LeTx has activity against two cellular compartments of tumors, malignant and endothelial cells. HUVEC are sensitive to LeTx growth inhibition. Thus, LeTx has an antiangiogenic activity, which is in agreement with the published evidence of reduced tumor neovascularization in experimental animals treated with PA and LF (23). The antiangiogenic properties of LeTx are also in agreement with the fact that the two receptors were identified in studies of activated or tumor endothelium. ANTXR2/CMG2 was first identified in HUVEC as a driver of tube formation in vitro, hence the name of capillary morphogenesis gene, while ANTXR1/TEM8 was identified as up-regulated in colorectal tumor endothelial cells compared to normal, donor-matched and colonic endothelial cells, hence the name of tumor endothelial marker (11-16, $38,39)$. From these important studies of angiogenesis, it appears that the killing of ANTXR2/CMG2- or ANTXR1/ TEM8-expressing endothelial cells by LeTx is a valuable and rational therapeutic approach.

The effect of LeTx in melanoma has been extensively studied in recent years and the therapeutic potential of LeTx in melanoma has become clear $(22-26,44)$. These studies suggest that LeTx may be clinically useful in other types of cancers such as neuroblastoma. The ANTXR1/TEM8 and ANTXR2/CMG2 protein expression should guide the choice of tumor models in which to test the effect of LeTx. Ultimately, ANTXR1/TEM8 and ANTXR2/CMG2 expression may help select patients who would benefit from LeTx therapy.

\section{Acknowledgements}

The authors are indebted to Dr Naoki Agata for assistance with Western blotting and to Matthew DeFronzo for assistance with Western blot quantification.

\section{References}

1. Prince AS: The host response to anthrax lethal toxin: unexpected observations. J Clin Invest 112: 656-658, 2003.

2. Welkos SL, Keener TJ and Gibbs PH: Differences in susceptibility of inbred mice to bacillus anthracis. Infect Immun 51: 795-800, 1986.

3. Moayeri M, Haines D, Young HA and Leppla SH: Bacillus anthracis lethal toxin induces TNF- $\alpha$-independent hypoxiamediated toxicity in mice. J Clin Invest 112: 670-682, 2003.

4. Agrawal A and Pulendran B: Anthrax lethal toxin: a weapon of multisystem destruction. Cell Mol Life Sci 61: 2859-2865, 2004.

5. Fukao T: Immune system paralysis by anthrax lethal toxin: the roles of innate and adaptive immunity. Lancet Infect Dis 4: 166-170, 2004

6. Warfel JM, Steele AD and D'Agnillo F: Anthrax lethal toxin induces endothelial barrier dysfunction. Am J Path 166: 1871-1881, 2005.

7. Moayeri M and Leppla SH: The roles of anthrax toxin in pathogenesis. Curr Opin Microbiol 7: 19-24, 2004.
8. Scobie HM and Young JAT: Interactions between anthrax toxin receptors and protective antigen. Curr Opin Microbiol 8: 106-112, 2005.

9. Melnyk RA and Collier RJ: A loop network within the anthrax toxin pore positions the phenylalanine clamp in an active conformation. Proc Natl Acad Sci USA 103: 9802-9807, 2006.

10. Krantz BA, Melnyk RA, Zhang S, Juris SJ, Lacy DB, Wu Z, Finkelstein BA and Collier RJ: A phenylalanine clamp catalyzes protein translocation through the anthrax toxin pore. Science 309: 777-781, 2005 .

11. St. Croix B, Rago C, Velculescu V, et al: Genes expressed in human tumor endothelium. Science 289: 1197-1202, 2000.

12. Bradley KA and Young A: Anthrax toxin receptor proteins. Biochem Pharmacol 65: 309-314, 2003.

13. Nanda A, Carson-Walter EB, Seaman S, Barber TD, Stampfl J, Singh S, Vogelstein B, Kinzler KW and St. Croix B: TEM8 interacts with the cleaved C5 domain of collagen alpha 3(VI). Cancer Res 64: 817-820, 2004.

14. Nanda A and St. Croix B: Tumor endothelial markers: new targets for cancer therapy. Curr Opin Oncol 16: 44-49, 2004.

15. Bell SE, Mavila A, Salazar R, Bayless K, Kanagala S, Maxwell SA and Davis GE: Differential gene expression during capillary morphogenesis in 3D collagen matrices: regulated expression of genes involved in basement membrane matrix assembly, cell cycle progression, cellular differentiation and Gprotein signaling. J Cell Sci 114: 2755-2773, 2001.

16. Scobie HM, Rainey GJ, Bradley KA and Young JA: Human capillary morphogenesis protein 2 functions as an anthrax toxin receptor. Proc Natl Acad Sci USA100: 5170-5174, 2003.

17. Mogridge J, Cunningham K, Lacy DB, Mourez M and Collier RJ: The lethal and edema factors of anthrax toxin bind only to oligomeric forms of the protective antigen. Proc Natl Acad Sci USA 99: 7045-7048, 2002.

18. Rainey GJ, Wigelsworth DJ, Ryan PL, Scobie HM, Collier RJ and Young JAT: Receptor-specific requirements for anthrax toxin delivery into cells. Proc Natl Acad Sci USA 102: 13278-13283, 2005.

19. Chopra AP, Boone SA, Liang X and Duesbury NS: Anthrax lethal factor proteolysis and inactivation of MAPK kinase. J Biol Chem 278: 9402-9406, 2003.

20. Bann JG, Cegelski L and Hultgren SJ: LRP6 holds the key to the entry of anthrax toxin. Cell 124: 1119-1121, 2006.

21. Monks A, Scudiero D, Skehan P, et al: Feasibility of a high-flux anticancer drug screen using a diverse panel of cultured human tumor cell lines. J Natl Cancer Inst 83: 757-766, 1991.

22. Duesbery NS, Webb CP, Leppla SH, et al: Proteolytic inactivation of MAP-kinase-kinase by anthrax lethal factor. Science 280 : 734-737, 1998.

23. Duesbery NS, Resau J, Webb CP, et al: Suppression of ras-mediated transformation and inhibition of tumor growth and angiogenesis by anthrax lethal factor, a proteolytic inhibitor of multiple MEK pathways. Proc Natl Acad Sci USA 98: 4089-4094, 2001.

24. Koo HM, VanBrocklin M, McWilliams MJ, et al: Apoptosis and melanogenesis in human melanoma cells induced by anthrax lethal factor inactivation of mitogen-activated proten kinase kinase. Proc Natl Acad Sci USA 99: 3052-3057, 2002.

25. Abi-Habib RJ, Singh R, Leppla SH, et al: Systemic anthrax lethal toxin therapy produces regressions of subcutaneous human melanoma tumors in athymic nude mice. Clin Cancer Res 12: 7437-7443, 2006.

26. Abi-Habib RJ, Urieto JO, Liu S, et al: BRAF status and mitogenactivated protein/extracellular signal-regulated kinase kinase 1/2 activity indicate sensitivity of melanoma cells to anthrax lethal toxin. Mol Cancer Ther 4: 1303-1310, 2005.

27. Sugimoto T, Tatsumi E, Kemshead JT, Helson L, Green AA and Minowada J: Determination of cell surface membrane antigens common to both human neuroblastoma and leukemialymphoma cell lines by a panel of 38 monoclonal antibodies. $\mathrm{J}$ Natl Cancer Inst 73: 51-57, 1984.

28. Carey TE, Takahashi T, Resnick LA, Oettgen HF and Old LJ: Cell surface antigens of human malignant melanoma. I. Mixed hemadsorption assays for humoral immunity to cultured autologous melanoma cells. Proc Natl Acad Sci USA 73: 3278-3282, 1976.

29. Shiku HT, Takahashi T, Oettgen HF and Old LJ: Cell surface antigens of human malignant melanoma. II. Serological typing with immune adherence assays and definition of two new surface antigens. J Exp Med 144: 873-881, 1976.

30. Giard DJ, Aaronson SA, Todaro GJ, Arnstein P, Kersey JH, Dosik $\mathrm{H}$ and Parks WP: In vitro cultivation of human tumors: establishment of cell lines derived from a series of solid tumors. J Natl Cancer Inst 51: 1417-1423, 1973. 
31. Fogh J and Trempe G: New human tumor cell lines. In: Human Tumor Cells In Vitro. Plenum Press, pp115-120, 1975.

32. Herlyn M, Balaban G, Bennicelli J, Guerry D IV, Halaban R, Herlyn D, Elder DE, Maul GG, Steplewski Z, Nowell PC, et al: Primary melanoma cells of the vertical growth phase: similarities to metastatic cells. J Natl Cancer Inst 72: 283-289, 1985.

33. Leibovitz A, Stinson JC, McCombs WB III, McCoy CE, Mazur KC and Mabry ND: Classification of human colorectal adenocarcinoma cell lines. Cancer Res 36: 4562-4569, 1976.

34. Trempe GL: Human breast cancer in culture. Recent Results Cancer Res 57: 33-41, 1976.

35. Soule, HD, Vasquez J, Long A, Albert S and Brennan M: A human cell line from a pleural effusion derived from a breast carcinoma. J Natl Cancer Inst 51: 1409-1416, 1973.

36. Eisenthal A, Babarsteyn E, Gitstein G and Lifschitz-Mercer B: Inhibition of lymphokine-activated killer cells generation in vitro by soluble factors released from mixed human tumor and peripheral blood mononuclear adherent cell culture. Cancer Invest 24: 28-34, 2006.

37. Chappell DB, Zaks TZ, Rosenberg SA and Restifo NP: Human melanoma cells do not express fas (Apo-1/CD95) ligand. Cancer Res 59: 59-62, 1999.

38. Park S and Leppla SH: Optimized production and purification of Bacillus anthracis lethal factor. Protein Expr Purif 18: 293-302, 2000.

39. Ramirez DM, Leppla SH, Schneerson R and Shiloach J: Production, recovery and immunogenicity of the protective antigen from a recombinant strain of Bacillus anthracis. J Ind Microbiol Biotechnol 28: 232-238, 2002.

40. Ishiyama $\mathrm{M}$, Tominaga $\mathrm{H}$, Shiga $\mathrm{M}$, et al: A combined assay of cell viability and in vitro cytotoxicity with a highly watersoluble tetrazolium salt, neutral red and crystal violet. Biol Pharm Bull 19: 1518-1520, 1996.

41. Teicher BA, Holden SA, Ara G, Alvarez Sotomayor E, Huang ZD, Chen Y-N and Brem H: Potentiation of cytotoxic cancer therapies by TNP-470 alone and with other antiangiogenic agents. Int $\mathrm{J}$ Cancer 57: 920-927, 1994.
42. Papadopoulos N, Kinzler KW and Vogelstein B: The role of companion diagnostics in the development and use of mutationtargeted cancer therapies. Nature Biotech 24: 985-995, 2006.

43. Chon HS, Hu W and Kavanagh JJ: Targeted therapies in gynecologic cancers. Curr Cancer Drug Targets 6: 333-363, 2006.

44. Abi-Habib RJ, Singh R, Liu S, Bugge TH, Leppla SH and Frankel AE: A urokinase-activated recombinant anthrax toxin is selectively cytotoxic to many human tumor cell types. Mol Cancer Ther 5: 2556-2562, 2006.

45. Pellizzari R, Guidi-Rontani C, Vitale G, et al: Anthrax lethal factor cleaves MKK3 in marophages and inhibits the LPS/IFN gamma-induced release of NO and TNF alpha. FEBS Lett 462: 199-204, 1999.

46. Pellizzari R, Guidi-Rontani C, Vitale G, et al: Lethal factor of Bacillus anthracis cleaves the N-terminus of MAPKKs: analysis of the intracellular consequences in macrophages. Int J Med Microbiol 290: 421-427, 2000.

47. Tang G and Leppla SH: Proteasome activity is required for anthrax lethal toxin to kill macrophages. Infect Immun 67: 3055-3060,1999.

48. Shin S, Hur GH, Kim YB, et al: Intracellular calcium antagonist protects cultured peritoneal macrophages against anthrax lethal toxin-induced cytotoxicity. Cell Biol Toxicol 16: 137-144, 2000.

49. Bhatnagar R and Friedlander AM: Protein synthesis is required for expression of anthrax lethal toxin cytotoxicity. Infect Immun 62: 2958-2962, 1994.

50. Wei W, Lu Q, Chaudry GJ, Leppla SH and Cohen SN: The LDL receptor-related protein LRP6 mediates internalization and lethality of anthrax toxin. Cell 124: 1141-1154, 2006.

51. Young JJ, Bromberg-White JL, Zylstra C, Church JT, Boguslawski E, Resau JH, Williams BO and Duesbery NS: LRP5 and LRP6 are not required for protective antigenmediated internalization or lethality of anthrax lethal toxin. PLoS Pathog 3: e27, 2007.

52. Molnar DM and Altenbern RA: Alterations in the biological activity of protective antigen of Bacillus anthracis toxin. Soc Exp Biol Med 114: 294-297, 1963. 